The prognosis after adequate pericardial resection is good, and disability from progressive myocardial dysfunction is rarely seen.

We thank our colleagues, in particular Dr. D. Evan Bedford, Mr. J. R. Belcher, and Mr. K. S. Mullard, for permission to include in this report the patients under their care.

\section{REFERENCES}

Andrews, G. W. S., Pickering, G. W., and Sellors, T. H. (1948). Quart. F. Med., 17, 291 .

Burwell, C.'S. (1957). Circulation, 15, 161.

Chambliss, J. R., Jaruszewski, E. J., Brofman, B. L., Martin, J. F., and Feil, H. (1951). Ibid., 4, 816.

Deterling, R. A., and Humphreys, G. H. (1955). Ibid., 12, 30.

Dines, D. E., Edwards, J. E., and Burchell, H. B. (1958) Proc. Mayo Clin., 33, 93.

Emanuel, R. W., and Lloyd, W. E. (1962). Brit. Heart F., 24, 796.
Evans, W., and Jackson, F. (1952). Ibid., 14, 53.

Fitzpatrick, D. P., Wyso, E. M. Bosher, L. H., and Richardson, D. W. (1962). Circulation, 25, 484.

Gimlette, T. M. D. (1959), Brit. Heart 7., 21, 9.

Kaltman, A. J., Schwedel, J. B., and Straus, B. (1953). Amer. Heart Y., $45,201$.

Keith, T. A. (1962). Circulation, 25; 477.

Kisch, B., Nahum, L. H., and Hoff, H. E. (1940). Amer. Heart 7., 20, 174.

Mounsey, P. (1959). Brit. Heart 7., 21, 325

Paul, O., Castleman, B., and White, P.'D. (1948). Amer. f. med. Sci., 216, 361.

Roberts, J. T., and Beck, C. S. (1941). Amer. Heart F., 22, 314

Roberts, J. T., and Beck, C. S. (1941). Amer. Heart f., 22, 35.

Robertson, R., and Arnold, C. R. (1962). Circulation,

Schrire, V. (1959). S. Afr. med. ł., 33, 810.

Sellors, T. H. (1946). Brit. F. Surg., 33, 215.

Sen, P. K., Parulkar, G. B., Chhabria, N. D., and Dhruva, A. J. (1962). 7. Indian med. Ass., 39, 505.

Smith, G. W., and Muller, W. H. (1962). Progr. cardiovasc. Dis., 4, 346. White, P. D. (1935), Lancet, 2, 539597.

Wood, P. (1956). Diseases of the Heart and Circulation, 2nd ed. Byre and Spottiswoode, London.

\title{
Geographical and Tribal Distribution of the African Lymphoma in Uganda
}

\author{
DENIS BURKITT,* M.D., F.R.C.S.ED.; DENNIS WRIGHT, $\dagger$ B.SC., M.D., M.C.PATH.
}

Brit. med. F., 1966, 1, 569-573

The geographical distribution of the African lymphoma (Burkitt, 1963 ; Wright, 1963) on the Continent of Africa has been shown to correspond closely with certain environmental conditions, notably temperature and humidity (Burkitt, 1962). This geographical localization, together with the age incidence of the tumour, has formed the basis for the hypothesis that this tumour may be caused by an arthropod vectored virus. Most of the previous reports have dealt with the distribution of the tumour in Africa as a whole and have of necessity been rather superficial in certain aspects. This report gives a more detailed analysis of the age, tribal, and geographical distribution of 450 histologically proved cases of this tumour seen in Uganda over the past eight years.

In Giemsa-stained imprint preparations of the African lymphoma the lymphoid cells have a characteristic morphology (Wright, 1963). These cells are not found in other types of lymphoma or leukaemia (Pulvertaft, 1964) and we regard them as diagnostic of the African lymphoma. Many of the features of these cells can be recognized in sections of formalin-fixed tissue, enabling the diagnosis of African lymphoma to be made on histological criteria (Wright, in preparation). Although some of the clinical features of the African lymphoma, such as multiple jaw tumours and bilateral ovarian tumours, are almost pathognomonic of the condition, the diagnosis in all the cases recorded here was confirmed by cytology or histology.

\section{Topography, Vegetation, and Climate}

\section{Topography and Vegetation}

Most of the northern and eastern regions of Uganda lie at altitudes varying from 2,000 to 4,000 feet $(600$ to $1,200 \mathrm{~m}$.) above sea level (Fig. 1). Within these regions the only district

\footnotetext{
- Department of Surgery, Makerere University College Medical School Kampala, Uganda ; member of the External Scientific Staff of the Medical Research Council. † Department of Pathology, Makerere University College Medical School,
Kampala, Uganda.
}

above 4,000 feet is Karamoja, an arid semi-desert region sparsely populated by nomadic tribes. With the exception of the thinly populated area containing the Queen Elizabeth Game Park (marked G.P. on Fig. 1), all the western region is over 4,000 feet above sea level. Much of this area, including Kigezi District and the south-western part of Ankole (Fig. $2)$ is over 5,000 feet $(1,500 \mathrm{~m}$.) above sea level. Most of Uganda consists of low rolling hills' and plains covered by grass or bush savannah. There are large areas of papyrus swamp, particularly around Lake Kyoga and along the course of the Nile. To the west the broad grasslands of Ankole District rise to the steeply wooded hills of Kigezi District and the snow-capped peaks of the Mountains of the Moon. These highland areas are a continuation northwards of the huge mountainous plateau that forms most of Rwanda and Burundi and extends into north-western Tanzania. Most of the

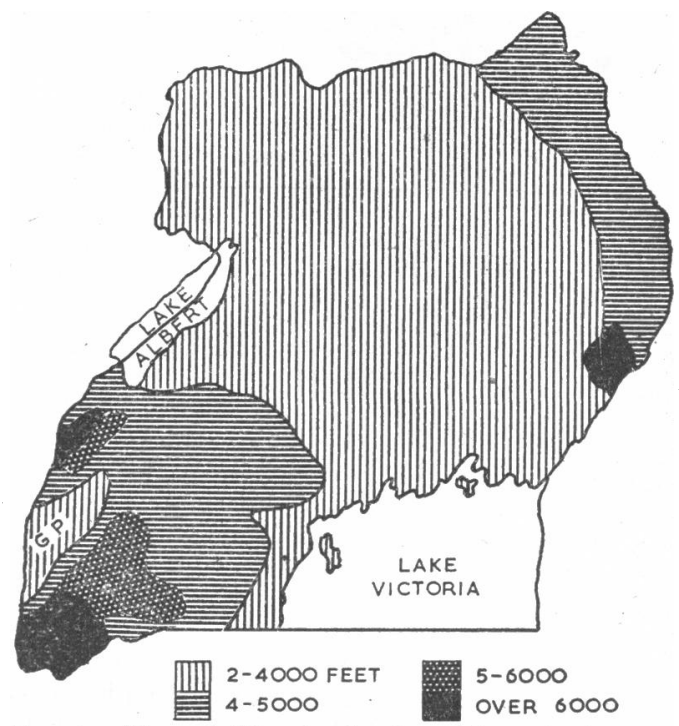

FIG. 1.-Map of Uganda showing altitudes above sea level. 
inhabited area of this plateau is over 6,000 feet $(1,800 \mathrm{~m}$.) above sea level.

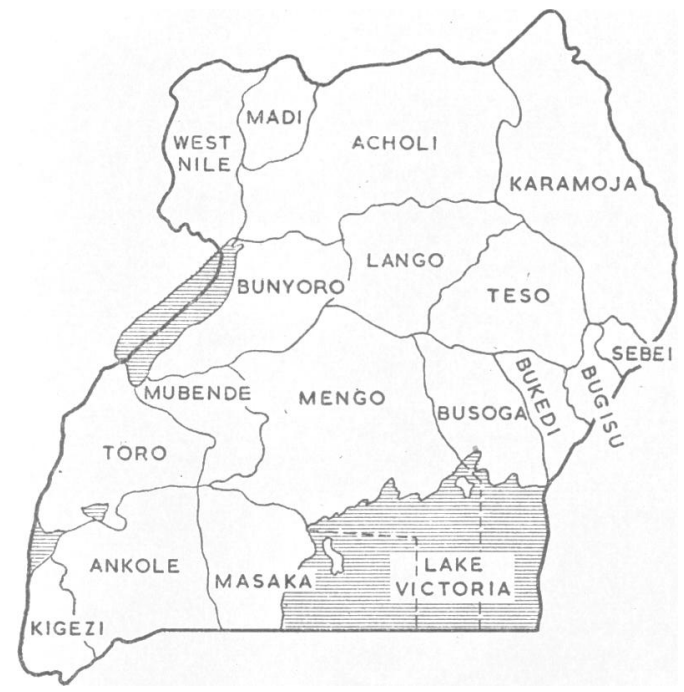

FIG. 2.-Map of Uganda showing districts. Buganda is composed of Mengo, Masaka, Mubende districts.

\section{Climate}

Temperature. The temperature in the south and west is considerably lower than in the north, east, and central parts of the country (Fig. 3). The only area of higher temperature and lower altitude within the western region (marked G.P. in Figs. 1 and 3) is largely occupied by a game reserve and is almost uninhabited.

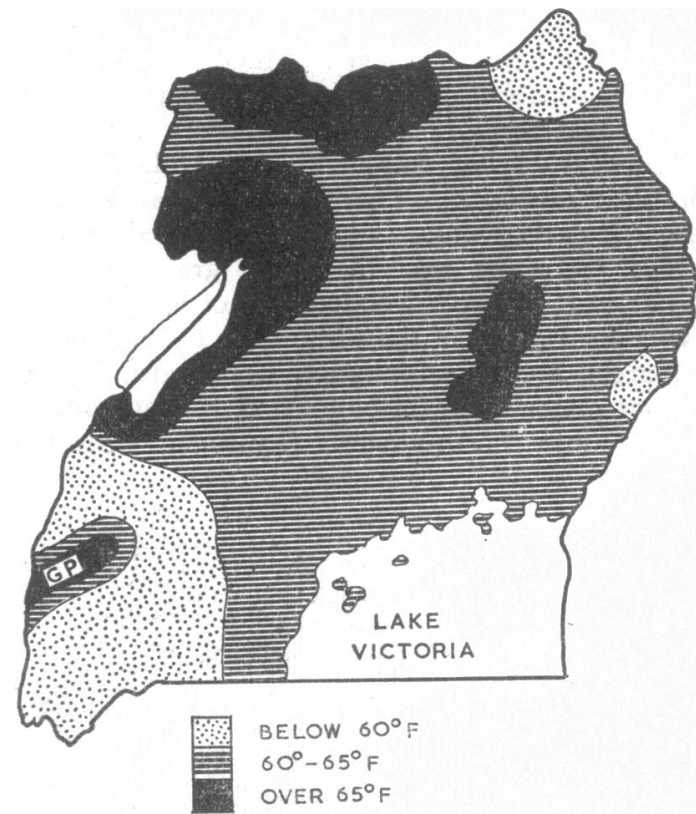

FIG. 3.-Map of Uganda showing mean annual minimum temperature.

Rainfall. Over most of the country the annual rainfall is between 40 and 60 inches (100 and $150 \mathrm{~cm}$.) a year. It is wetter in Kigezi and drier in Karamoja and Ankole.

\section{People}

Uganda is the meeting point of peoples of several different ethnological stocks. The Bantu line roughly bisects the country horizontally, marking the northern limit of the Bantu peoples. The tribes to the north of this line are broadly classified as Nilotic in origin. During the past centuries Hamitic tribesmen, probably originating from Ethiopia, have penetrated the country, bringing their long-horned cattle with them. Some of these Hamitic groups were completely integrated with the indigenous population; others have remained as isolated groups of pure Hamitic stock, as represented by the Bahima tribesmen of Ankole.

During the past three decades there has been a continuous immigration into Central Uganda of peoples from the neighbouring territories of Rwanda and Burundi. Some of these, mainly young adult males, have obtained temporary employment in the relatively prosperous central region of Uganda and have then returned to their native lands. The majority of the immigrants have, however, settled permanently in Uganda and according to the 1959 census form $20 \%$ of the population of Buganda.

\section{Geographical Distribution of Tumour}

In Fig. 4 tumour incidence is shown on the basis of the number of cases recorded from each district per 100,000 population over an 8-year period. With the exception of Karamoja, an arid and thinly populated area with few medical

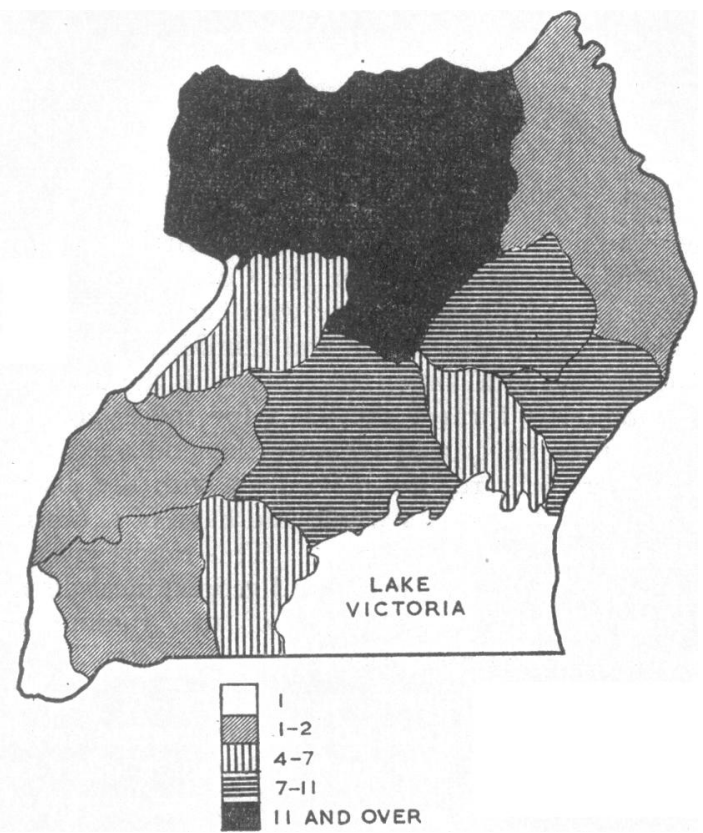

FIG. 4.-Number of patients with African lymphoma recorded per 100,000 population in eight years.

facilities, the tumour is much more prevalent in the northern eastern, and central regions than in the south and west. While the tumour incidence in the northern part of Uganda, with the exception of Karamoja, varies between 8.7 and 13.4 per 100,000 , it was less than 2 per 100,000 throughout Toro, Ankole, Mubende, and Kigezi in the west and south. The Kigezi incidence of 0.6 per 100,000 is less than one-twentieth of the incidence recorded from the north-west of the country.

It is unlikely that the patients with African lymphoma recorded here represent all the cases occurring in Uganda over the past eight years. Undoubtedly many cases never reach hospital, and a definitive diagnosis is unlikely to be made on all those that do seek medical aid. Nevertheless, the wide variations in tumour incidence within Uganda are unlikely to be due to variability in notification of the tumour. Communications and medical services in the south-west are at least as good as those in north-western Uganda. Many of the doctors in the south-west have worked in Kampala, are familiar with the features of the African lymphoma, and have 
been repeatedly urged to look out for it. Since 1961 the Kampala Cancer Registry has recorded all histologically proved malignant tumours reported from the whole of Uganda. African lymphoma accounts for $18 \%$ of all the malignant tumours recorded from north-western Uganda but for less than $1 \%$ of all malignant tumours recorded from south-western Uganda.

\section{Racial and Tribal Distribution}

\section{Racial Distribution}

With the exception of three Asians, all Uganda patients have been Africans. The ratio of African to Asian cases is thus approximately 150 to 1 . This corresponds almost exactly to the ratio of Africans to Asians in the general population of Uganda. The African to European ratio in the Uganda population is approximately 1,000 to 1. No European case of this tumour has yet been recorded in Uganda. It thus appears that racial characteristics do not affect susceptibility to this tumour.

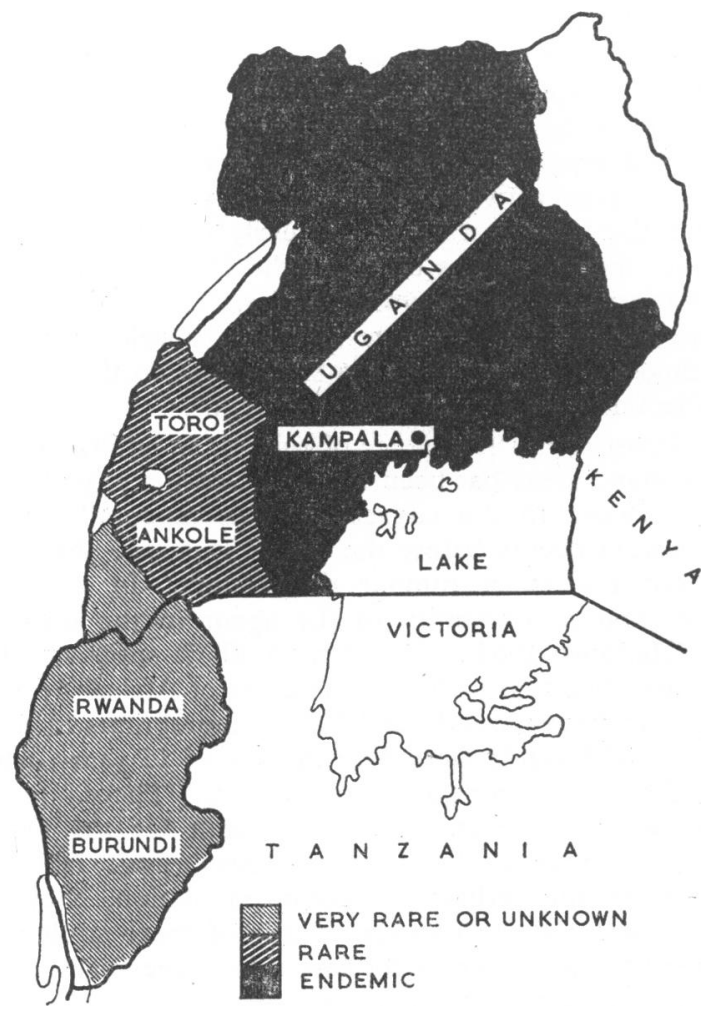

FIG. 5.- Map of Uganda, Rwanda, and Burundi, showing areas where the African lymphoma is endemic, rare, or almost unknown.

BUGANDA - POPULATION

\section{BAGANDA}

BANYARWANDA

BAKIGA

OTHERS

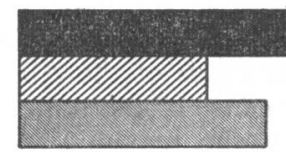

- CASES OF LYMPHOMA

BAGANDA

BANYARWANDA

BAKIGA

OTHERS

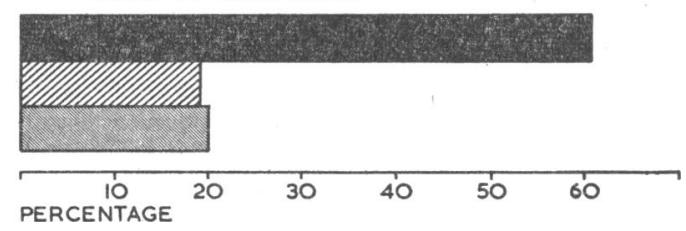

FIG. 6.-The proportion of Banyarwanda and Bakiga immigrants in the population of Buganda and the proportion of African lymphoma patients provided by this group.

\section{Tribal Distribution}

The cases of tumour analysed in this series come from 373 different tribes. These include all the major tribes in Uganda and members of some 13 tribes from surrounding countries resident in Uganda.

\section{Tumour Susceptibility of Immigrants from Tumour-free Areas}

The largest group of immigrants resident in Buganda are the Banyarwanda, Barundi, ${ }^{1}$ and Bakiga who have come from the "lymphoma-free" area (Rwanda, Burundi, and Kigezi) to the south-west (Fig. 5). These immigrants constitute $20 \%$ of the total population in Buganda (Fig. 6). It is particularly significant that $19 \%$ of all cases of African lymphoma recorded in Buganda were observed in the Banyarwanda and Bakiga (Fig. 6). It is thus evident that these immigrants from areas where the tumour is rarely, if ever, seen show a susceptibility to tumour development approximately equal to that of the indigenous population.

\section{Age Distribution Related to Tumour Incidence}

It has been shown that tumour incidence is highest in the north-west of Uganda and lowest in the south-west. Although the districts of Kigezi, Ankole, Toro, and Mubende represent almost $25 \%$ of the total population of Uganda, less than $4 \%$ of lymphomas have been observed in patients from these areas. The average age of the patients from these areas is 16.2 years. In contrast, the average age of patients from West Nile, Acholi, and Lango, where tumour incidence is highest, is 8.1 years.

\section{Age Distribution in Banyarwanda, Barundi, and Bakiga Immigrants}

The Banyarwanda and Bakiga living in Buganda are a heterogeneous group in terms of the duration of their residence in Buganda. Some are immigrant tribesmen who have recently arrived; others have settled homes and have lived in the district for many years or have been born in the district. Of all the African lymphomas recorded in Buganda $19 \%$ come from this immigrant group, which forms $20 \%$ of the population of Buganda. The age distribution of the tumour cases among the immigrant Banyarwanda and Bakiga is shown in Fig. 7. It will be seen that there is a large percentage of adult cases in this group. Nearly $50 \%$ of the patients are over 15 years and $26 \%$ are over 30 years.

\section{Jaw Tumours Related to Tumour Incidence}

Among patients from the tumour endemic areas of West Nile, Acholi, and Lango $57.5 \%$ of patients had jaw tumours. In the south-western districts, where the tumour is rare, the jaws were involved in only $30.5 \%$ of patients. This difference is attributed to the difference in age incidence of the tumour in the two areas, since jaw lesions are known to be more prevalent in the younger age groups (Fig. 8).

\section{Sex Incidence}

The overall sex incidence is 2.3 males to 1 female. This figure undoubtedly represents a true preponderance of males

\footnotetext{
"The term "Banyarwanda" will be used, as is customary locally, to
} denote both the Banyarwanda and the Barundi. 
with the tumour, since the admission rates to the paediatric wards are equal for males and females and the sex ratio for the cases of Wilm's tumour and retino-blastoma recorded in the Kampala Cancer Registry is approximately unity.
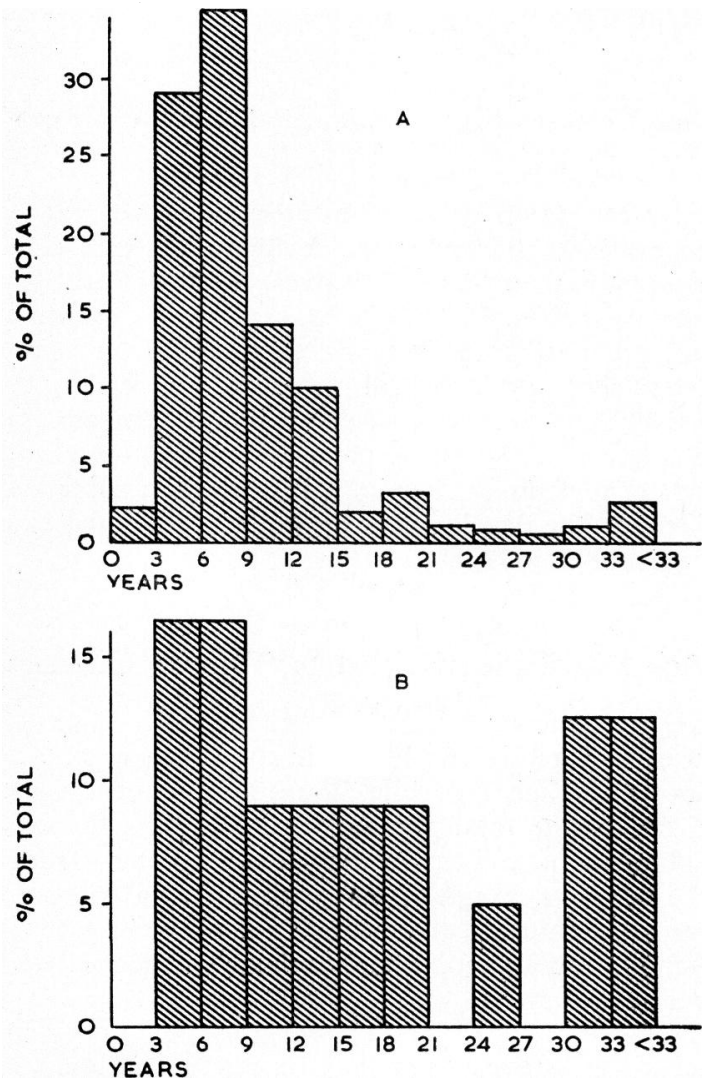

FIG. 7 (A).-Overall age distribution of African lymphom in Uganda (B) Age distribution of African lymphoma in Banyarwanda and Bakiga immigrants to Buganda.

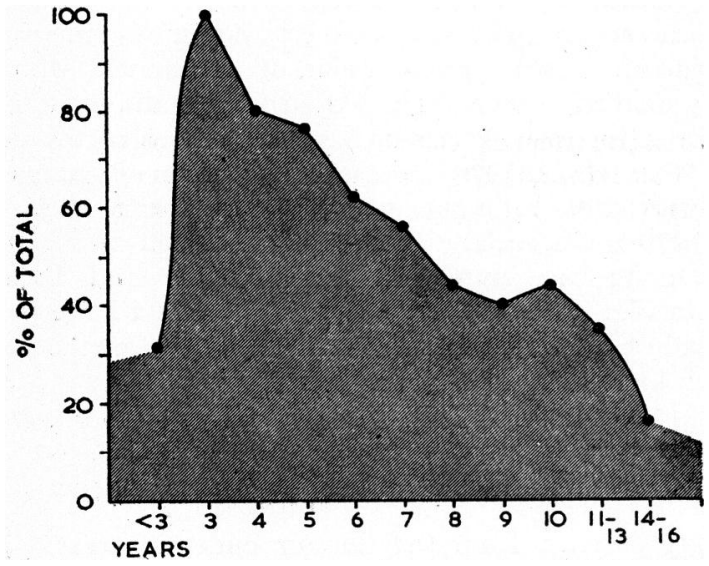

FIG. 8.-Percentage of patients with jaw lesions in each age group.

\section{Discussion}

There are wide variations in the incidence of the African lymphoma within Uganda. The tumour is most common in the hot lowland areas, north of Lake Kyoga and along the valley of the Albert Nile, and is least common in the cool mountainous area of south-western Uganda. This latter area is a continuation of the mountainous plateau that forms most of Rwanda and Burundi. The twentyfold difference in tumour incidence between these two areas cannot be explained on the basis of hospital facilities and communications, which are at least as good in south-western Uganda as in north-western
Uganda. The difference cannot be explained on the basis of genetic factors, since all tribes and races living within the lowland areas appear to be equally susceptible to the tumour, and, in addition, the tumour incidence in immigrants from the highland to the lowland areas is approximately equal to that of the local indigenous population. The variation in tumour incidence within Uganda correlates closely with temperature, which is in turn matched by variations in vegetation and insect populations.

Haddow (1964) has shown that the cumulative age incidence curve for the African lymphoma is very similar to that for yellow fever antibodies in Bwamba County, Uganda. This observation is consistent with the hypothesis that the African lymphoma may be induced by an insect vectored virus. The absence of cases in the first two years of life might be due to maternal antibodies to the virus protecting the child during these years. It might also be due to a minimal induction period of two years for the tumours. In the series of cases reviewed here only $2 \%$ were under the age of 3 and only a single case was under the age of 2 years.

After the age of 2 the tumour incidence rises steeply, reaching a peak in the 3- to 8-year period. When analysed on a regional basis in Uganda it is seen that the average age in the tumour cases is lowest where the tumour is most common and highest where the tumour is least common. This observation supports the hypothesis that there may be an environmental factor stimulating tumour production. It is suggested that in the lowland areas the chance of contact with this factor is greatest, that exposure occurs at an early age, and as a consequence the tumour develops in early childhood. In areas where the tumour is less common the chance of exposure to the environmental factor would be less, and the age of contact later, resulting in later tumour development. The epidemiology of this tumour has similarities in this respect to the epidemiology of paralytic poliomyelitis.

The almost complete absence of tumour in adults indigenous to the lowland areas has been explained on the hypothesis that initial exposure to the suggested environmental carcinogen almost always occurs before the age of 15 years. Exposure to this agent results in tumour development in a very few instances and in immunity to the agent in the majority of people (Haddow, 1964). This hypothesis is supported by the observation that nearly $50 \%$ of the cases of African lymphoma occurring in Banyarwanda and Bukiga immigrants to the lowland areas of Uganda were over the age of 15 years, and that $26 \%$ of them were over the age of 30 years. These immigrants presumably met the environmental agent for the first time when they entered the lowland areas, and, lacking the immunity of the indigenous adult population, they subsequently developed the tumour. Some of these adult patients had lived in lowland areas for less than three years, and they may give a clue to the induction period of the tumour. A more detailed analysis of these adult cases is now in preparation.

One of the most striking features of the African lymphoma is its predilection for the bones of the jaw and the face. This predilection varies with the age of the patient, being greatest at the age of 3 years and falling thereafter. The incidence of jaw tumours in any series of cases of the African lymphoma will thus vary with the prevalence of the tumour in the population. The years at which the maximal incidence of jaw tumours occurs are those of greatest developmental activity of the dental elements of the jaw. They may also coincide with the age at which the mouth is colonized by herpes simplex and the other viruses of the herpes group. Herpes simplex and herpes-like viruses have been isolated from several biopsies of the Africa lymphoma and cannot be excluded as possible co-carcinogens (Woodall and Haddow, 1962 ; Simons and Ross, 1963 ; Epstein et al., 1965).

This study of the geographical, tribal, and age distribution of the African lymphoma in Uganda supports the hypothesis 
that this tumour may be induced by an environmental factor. The age distribution both in the indigenous and in the immigrant population suggests that this factor produces immunity in the majority of people exposed to it and tumour only in rare instances. The apparent dependence on temperature of the tumour distribution suggests that the environmental agent is transmitted by an insect vector and that either the distribution of the vector or the development of the agent within the vector is dependent on temperature. This agent might be an arbovirus or other insect-vectored virus; it could also be some other form of parasitic disease such as malaria.

\section{Summary}

This report gives a detailed analysis of the age, tribal, and geographical distribution of 450 histologically proved cases of the African lymphoma seen in Uganda over the past eight years. There is a twentyfold difference between the tumour incidence in the lowland areas along the Nile, where the tumour is most common, and the incidence in the mountainous area of south-western Uganda, where the tumour is least common. This variation in incidence within Uganda correlates closely with variations in temperature. The average age in the tumour cases is lowest where the tumour is most common and highest where the tumour is least common.

The incidence of jaw involvement in the Uganda cases of African lymphoma varies inversely with the age of the patient. It is $100 \%$ at the age of 3 and falls progressively thereafter. Although the African lymphoma is rare in adults indigenous to the lowland areas of Uganda, almost half the cases occurring in immigrants from the "lymphoma-free" mountainous area of Rwanda and Burundi are over the age of 15 years.

These observations support the hypothesis that the African lymphoma may be induced by an insect-vectored agent that may be a virus. It is suggested that the majority of people exposed to this agent develop immunity to it and that in only rare instances is the tumour induced.

All the illustrations are gratefully acknowledged to W. Serumaga and E. Busulwa, of the Department of Medical Illustration in the Makerere University College Medical School. Fig. 8 was taken from the fournal of Dental Research.

We also wish to thank the doctors in Government and Mission hospitals throughout the country for their co-operation, without which these investigations could not be undertaken.

We are indebted to the Kampala Cancer Registry for much of the information, and to Dorothy Griffin for invaluable secretarial assistance.

The British Empire Cancer Campaign have provided financial assistance to make this work possible.

\section{REFERENCRS}

Burkitt, D. (1962). Brit. med. f., 2, 1019.

(1963). In International Review of Experimental Pathology, vol. 2 , ed. G. W. Richter and M. A. Epstein. Academic Press, New York. Epstein, M. A., Henle, G., Achong, B. G., and Barr, Y. M. (1965). F. exp. Med., 121, 761 .

Haddow, A. J. (1964). E. Afr. med. ₹., 41, 1.

Simons, P. J., and Ross, M. G. R. (1963). Ann. Rep. Imp. Cancer Res. Fund, p. 48. London.

Woodall, J. P., and Haddow, A. J. (1962). E. Afr. Res. Inst. Rep., p. 30. Wright, D. H. (1963) Brit. f. Cancer, 17, 50 .

\title{
Recurrence of Aortic Coarctation after Operation in Childhood
}

\author{
CLIFFORD G. PARSONS,* M.D., F.R.C.P. ; ROY ASTLEY, $†$ M.D., D.M.R.
}

Brit. med. F., 1966, 1, 573-577

Evidence about the results of operating on small children with coarctation of the aorta is conflicting, and there is still doubt whether the anastomosis grows with the child. "Until definite evidence can be obtained that an aortic anastomosis made during childhood will remain adequate in size in adult life, operation is better deferred until about the age of 15 in children without symptoms" (Sellors and Hobsley, 1963). Schuster and Gross (1962) advise the use of interrupted sutures because spaces between the stitches can allow growth to occur. Continuous sutures, technical difficulties caused by a long narrow segment of aorta, and operating on seriously ill infants are all factors which are thought to reduce the chance of obtaining a satisfactory anastomosis (Mustard et al., 1955 ; Bull et al., 1963).

Few accounts of restenosis have been published, however, either because of reluctance to record poor operative results or because such cases are rare. Rathi and Keith (1964) have reviewed the long-term results in 150 children who were treated surgically before they were 15 years old. Of these, 27 had an operation in their first year. They conclude that there is usually adequate growth of the anastomotic site even if operation is performed in infancy, and they found no evidence to indicate development of obstruction or restenosis from lack of localized arterial growth.

\footnotetext{
- Physician, Birmingham United Hospital and Children's Hospital, Birmingham. † Radiologist, Children's Hospital, Birmingham.
}

About a quarter of patients with coarctation die during infancy (Blackford, 1928), but a child surviving the first year is unlikely to die before its tenth birthday (Reifenstein et al., 1947). The mortality rate increases again in the second decade, and it is therefore unwise to delay operation after puberty (d'Abreu and Parsons, 1956). Rathi and Keith (1964) advise operation between 3 and 6 years of age, but in the large series of cases reported by Schuster and Gross (1962) operative mortality was at its lowest $(1.6 \%)$ at about the tenth year. In infancy surgical mortality is much higher, Nadas (1963) quoting a range "from 25 to $40 \%$, without guarantee of satisfactory and permanent relief of the hypertension." For this reason most paediatricians believe that heart failure associated with coarctation in infancy should be treated medically and that operation should be advised only in resistant cases (Lang and Nadas, 1956 ; Freundlich et al., 1961).

Persistent heart failure has made it necessary for us to advise operation on 13 babies, and three of these died. Among the survivors five appeared to develop recurrence of their aortic stricture. Other examples of restenosis have been observed in five older children. It is with these 10 cases of recurrent coarctation that this paper is concerned.

Before operation all the patients were shown to have localized constriction of the aortic arch, and this was confirmed by the pathologists who examined specimens after excision. In addition, three children had a somewhat narrow hypoplastic segment above the abrupt constriction. Some complicating 